\title{
Filosofía del Derecho Contractual
}

\author{
Lucas S. Grosman
}

Recepción y evaluación de propuesta: 20/7/13

Aceptación: 15/10/2013

Recepción y aceptación final: 30/12/14

Resumen: Los cuatro trabajos que componen este número se embarcan en una discusión sobre el mejor modo de entender y justificar el derecho de los contratos. El trabajo de Martín Hevia sintetiza las principales ideas de su libro Reasonableness and Responsibility, donde usa como plataforma las ideas centrales de John Rawls sobre la organización básica de la sociedad y la teoría del derecho contractual de Kant.

Palabras clave: derecho de los contratos, voluntad individual y seguridad jurídica.

Abstract: The four essays that compose this issue treat about a discussion on which is the the best way of understanding and justifying the contract law. The work of Martín Hevia synthesizes the main ideas of his book Reasonableness and Responsibility, where he uses the leading John Ralw's ideas about the basic organization of society and Kant's contract law theory.

Keys words: contract law, individual will and legal security

Los editores de esta revista me han honrado con la tarea de coordinar y prologar este número dedicado a discutir el trabajo de Martín Hevia "Razonabilidad y Responsabilidad: Rawls, Kant y la teoría del derecho contractual", que sintetiza las principales ideas de su libro

* Universidad de San Andrés (Buenos Aires, Argentina).

Email:1grosman@udesa.edu.ar 
Reasonableness and Responsibility. Tres expertos en derecho contractual y filosofía del derecho privado han tenido la enorme gentileza de sumarse a la discusión: Mauricio Rengifo, Íñigo de la Maza y Diego Papayannis.

Los cuatro trabajos que componen este número se embarcan en una discusión fascinante y sofisticada, que nos invita a reflexionar sobre el mejor modo de entender y justificar el derecho de los contratos. Como el lector podrá advertir, aunque los ángulos desde los cuales los tres comentaristas se aproximan al texto de Hevia son diferentes, existe un terreno común que permite reconstruir un diálogo multidireccional, y no meramente radial, entre todos ellos.

El propósito de Hevia es usar como plataforma las ideas centrales de John Rawls sobre la organización básica de la sociedad para abordar un área que ese filósofo político no trató de manera específica: el derecho de los contratos. En esta tarea, Hevia apela a la teoría del derecho de los contratos de Kant, autor en cuya tradición cabe inscribir a Rawls y que, por ende, puede resultar de relevancia a la hora de complementar su obra.

De la Maza, siguiendo a Smith ${ }^{1}$, sugiere que la teoría de Hevia es interpretativa. Hevia acepta de buen grado esta caracterización, y explica que su teoría procura darle sentido al derecho o iluminarlo, tarea esta sin dudas más compleja, pero también mucho más interesante que la de describirlo y que, indefectiblemente, deberá dar cuenta del punto de vista interno de los agentes que participan en la práctica en cuestión.

Los tres comentaristas se muestran escépticos, aunque en grados variables, acerca de la posibilidad de reconstruir la práctica del derecho contractual a partir de un modelo rawlsiano-kantiano, en donde la voluntad individual ocupa un lugar central como fuente de normatividad. Aunque no es el objeto principal de su crítica, Rengifo plantea sus resquemores al respecto de manera más general y desliza que Hevia incurre en una inconsistencia importante: mientras que la

1 Smith, S. <A., Contract Theory, New York, Oxford University Press, 2004. 
filosofía kantiana del derecho está comprometida con la idea de una voluntad libre y es, por ende, subjetivista, la noción de expectativas razonables que sostiene Hevia tiene un elemento claramente objetivo.

Para entender el punto, vale la pena plantear un ejemplo. Supongamos que una persona A tiene la voluntad de celebrar un contrato con un contenido $\mathrm{X}$, pero su contraparte $\mathrm{B}$ entiende que el contenido es $\mathrm{Y}$. Las palabras utilizadas por $\mathrm{A}$ han generado en $\mathrm{B}$ una expectativa razonable de que el contenido es $\mathrm{Y}$, no X. Dicho de otra manera, A subjetivamente quería $\mathrm{X}$, pero un análisis objetivo de su manifestación de la voluntad lleva a concluir que sus palabras razonablemente deberían ser interpretadas en el sentido Y, que es lo que B hizo. En un caso así, el derecho positivo tiende a favorecer la interpretación Y. Hevia favorece el mismo resultado, lo cual, a juicio de Rengifo, podría ser contradictorio con su visión kantiana.

En respuesta a esta crítica, Hevia señala que, en realidad, es inevitable que el derecho recurra a un estándar objetivo cuando no coincide lo que subjetivamente entienden las dos partes de un contrato. Al fin y al cabo, en este caso son dos las subjetividades y ellas están en conflicto. ¿Nos compromete esto con un criterio consecuencialista, como cree Rengifo? No necesariamente. Aunque, sin dudas, existen razones de esa índole para privilegiar aquella interpretación subjetiva que más se acerca a la "objetiva" — en esencia, consideraciones de seguridad jurídica, tal como señala De la Maza-, entiende Hevia que también hay razones de índole kantiana que avalan que nos apoyemos en la idea de expectativas razonables.

En cualquier caso, la crítica que Rengifo desarrolla de manera más acabada se centra en un aspecto específico del derecho de los contratos y se nutre de un punto de vista histórico, vinculado con la evolución del derecho contractual, aunque con claras implicancias conceptuales o interpretativas. En tal sentido, sostiene Rengifo que la visión de Hevia no logra capturar dos desarrollos fundamentales de la práctica contractual: las condiciones generales de contratación o contratos por adhesión y las situaciones de hecho. En el caso de los contratos por adhesión, una parte, típicamente una empresa, predispone las cláusulas contractuales y la contraparte, en general un consumidor, decide 
solo si contrata o no, pero si lo hace no podrá cambiar ni una coma. En las llamadas situaciones contractuales de hecho, el contrato nace a partir de la realización de determinada conducta típica, como por ejemplo subir a un colectivo o ingresar a una playa de estacionamiento.

Tanto en el caso de los contratos por adhesión como en el de las situaciones contractuales de hecho, la libertad contractual se ve limitada de manera sustancial, ya que no existe negociación alguna sobre el contenido del contrato. La respuesta estatal ante estos fenómenos ha sido una intensa regulación mediante cláusulas imperativas, lo cual puede lograr que los contratos sean más equitativos o justos, pero no restablecer la libertad contractual perdida. Como dice De la Maza, en estos casos se apela a una noción de justicia que no surge de los términos del contrato, como presupone el modelo kantiano, sino que es externa a él. Dado que la teoría de Hevia no incluye un criterio para establecer el contenido de esta justicia externa al contrato, en este punto, dice De la Maza, "nos deja a ciegas".

Papayannis alude al mismo problema, aunque lo hace desde un ángulo distinto: para él, la prevalencia de normas regulatorias de los contratos de adhesión es un signo de que el derecho de los contratos es un ámbito regido, al menos en buena medida, por reglas de justicia distributiva, más cercanas al derecho público que al privado, mientras que la teoría de Hevia presupone el imperio de la justicia correctiva. Otro tanto puede decirse en relación con las normas que dejan de lado la voluntad de las partes por considerar que ella llevaría a situaciones injustas, aunque ello dependa no ya del aprovechamiento de una por otra, sino de circunstancias objetivas sobrevinientes, como ocurre en el caso de la teoría de la imprevisión. Incluso el efecto relativo de los contratos - que ellos sean obligatorios solo para las partes- es, a juicio de Papayannis, un principio menos absoluto de lo que la teoría de Hevia parece presuponer.

Los tres comentaristas, entonces, plantean que la teoría de Hevia no logra capturar de manera adecuada áreas importantes del derecho de los contratos, en particular en aquellos supuestos en los que no existen instancias de negociación y la relación tiende a regirse por normas imperativas. Coinciden también en que Hevia no puede alegar 
que las relaciones en cuestión no sean verdaderos contratos ni que prescinda de ellas en su teoría, pues se trata de un fenómeno central, no meramente marginal, dentro de la práctica contractual actual.

El desafío para Hevia no es menor: debe rescatar el poder interpretativo de una teoría basada en la libertad contractual en un mundo en el que esa libertad se ha visto notablemente relativizada. En su respuesta incluida en el quinto y último texto de este volumen, Hevia se hace cargo de este desafío. A su juicio, las objeciones referidas a las situaciones contractuales de hecho y a los contratos por adhesión merecen respuestas diferentes. Contrariamente a lo afirmado por Rengifo, Hevia entiende que las primeras sí pueden ser capturadas por su teoría. Ello es así por dos razones distintas. En primer lugar, la voluntad de contratar, aunque en estos casos no se vea plasmada de manera expresa, puede inferirse de acciones u omisiones típicas: "si el agente no quisiera vincularse contractualmente, se hubiera comportado de otra manera", dice Hevia. Estas acciones u omisiones serían un consentimiento tácito, pero consentimiento al fin.

Cabe aventurar que Rengifo no se sentiría satisfecho con esta respuesta. Como él explica, "el significado social de la conducta típica prevalece incluso por encima de las declaraciones de voluntad del agente (...) incluso en contra de la protesta del agente mismo". Supongamos, por ejemplo, que yo realizo la conducta "típica" (por ejemplo, subir al ómnibus), pero dejo asentado de manera fehaciente que no pretendo con ello sujetarme a las tarifas exhibidas en un letrero, que considero excesivas, sino a otras distintas, más razonables que aquellas. En un caso así donde mi voluntad expresa se contrapone a lo que Hevia consideraría mi voluntad tácita, tenderá a prevalecer la segunda, lo cual parece problemático para la respuesta que él nos ofrece. En efecto, no se trata aquí de inferir mi voluntad, sino de dar preeminencia a ciertos hechos que reflejan de manera imperfecta mi voluntad por sobre otros que lo hacen de manera más acabada. Tiendo a creer, en consecuencia, que el recurso a una voluntad tácita no termina de responder satisfactoriamente a la objeción de Rengifo.

Como segunda respuesta a este problema, Hevia explica que los servicios masivos en el marco de cuya prestación se producen 
las situaciones contractuales de hecho no podrían brindarse de otra manera. Los costos de transacción derivados de recurrir a mecanismos tradicionales de negociación y celebración de contratos serían prohibitivos. En tales condiciones, resulta razonable que las personas se vean vinculadas contractualmente de este modo, pues de lo contrario no podrían gozar de los servicios en cuestión, o lo harían a un precio mucho más alto. Por ello, concluye Hevia, "es justo que aceptemos estos términos de interacción social".

Creo que el argumento de Hevia es esencialmente correcto, pero resulta difícil de conciliar con su teoría. En algún punto, sigue las líneas generales del famoso planteo de Calabresi y Melamed relativo a las reglas de propiedad y responsabilidad como mecanismos alternativos para proteger derechos ${ }^{2}$. En el esquema propuesto por estos autores, cuando un derecho está protegido por una regla de propiedad, su titular solo puede ser privado de él si así lo consiente y al precio por él aceptado. En cambio, si un derecho está protegido por una regla de responsabilidad, el titular puede ser privado de él de manera compulsiva a cambio del precio colectivamente determinado a tal efecto. Mi derecho sobre mi casa está protegido en general por una regla de propiedad pero frente al riesgo de expropiación por causa de utilidad pública solo está protegido por una regla de responsabilidad. Para Calabresi y Melamed, el mecanismo de protección por defecto es la regla de propiedad, que garantiza que ambas partes en la transacción estarán mejor que antes, pero se justifica pasar a una regla de responsabilidad cuando los costos de transacción tornarían la regla de propiedad inviable ${ }^{3}$. Es decir, la justificación para no exigir el consentimiento es que si lo hiciésemos, una actividad socialmente valiosa se perdería por tornarse inviable, en perjuicio de todas las

2 Calabresi, G. y Melamed, A. D., Property rules, liability rules and inalienability: One view of the cathedral, Harvard Law Review, 1972.

3 En el ejemplo de la expropiación, los costos de transacción involucrados se vinculan con problemas de coordinación tanto del lado de la oferta (problemas de hold out) como de la demanda (problemas de free rider) del bien en cuestión. 
partes involucradas. Esto es, como vimos, precisamente lo que señala Hevia en el caso de ciertas relaciones contractuales.

Sin embargo, como adelanté, no creo que esta línea argumental esté disponible dentro del marco de la teoría general del contrato que propone Hevia. Si aceptamos que prescindir o apartarse del consentimiento real está justificado siempre que eso sea algo que, ex ante, un individuo racional debería aceptar porque es en su propio beneficio, la centralidad del consentimiento real plasmado en el contrato se desdibujaría de manera significativa. De hecho, no estaría claro por qué no deberíamos prescindir del consentimiento de manera más general, y no solo en los particulares casos en los que exigirlo sería inviable. Al fin y al cabo, en un sinnúmero de casos puede parecer razonable dejar de lado el consentimiento de las personas en procura de su bienestar, pero tal consideración debería ser insuficiente o incluso irrelevante para un kantiano. Creo que, necesariamente, la respuesta de Hevia tiene que ser más acotada; tiene que explicar por qué en estos casos, y no en otros, se justifica prescindir del consentimiento.

Entiendo que los mismos reparos podría generar la respuesta que Hevia brinda a las objeciones referidas a los contratos por adhesión. En este caso, Hevia opta por conceder de entrada que su teoría debe ser revisada para poder capturar este tipo de situaciones contractuales. Sin embargo, su concesión es más general ya que recoge las críticas al presupuesto de la racionalidad instrumental del agente que hacen distintos autores, en especial aquellos que escriben desde disciplinas que procuran analizar de manera realista la conducta humana, como behavioral law and economics. Hevia incluso admite que esta relativización de la importancia de la voluntad permitiría abrir la puerta a consideraciones de justicia distributiva, como promueve Papayannis.

La permeabilidad de Hevia a este tipo de críticas es de carácter preliminar y, sin dudas, podrá ser revisada más cuidadosamente. Sin embargo, me temo que, como en el caso de las situaciones contractuales de hecho, existe un riesgo importante de que, con las revisiones que Hevia parece dispuesto a efectuar, su teoría se desdibuje y se convierta en algo muy diferente a lo que aquí ha presentado. No parece, en 
tal sentido, que una teoría inscripta en la tradición kantiana tenga demasiado margen para soslayar la centralidad del consentimiento autónomo.

Tal vez sea muy pronto para decirlo; habrá que esperar a que las críticas sedimenten y a que Hevia las asimile y las procese. Por ello, no me animo a predecir el impacto sustantivo que, finalmente, tendrá este ejercicio en la teoría contractual de Hevia. Pero de algo estoy seguro: esta discusión ha enriquecido de manera formidable nuestra comprensión del fenómeno jurídico que estos cuatro autores han abordado. Solo me resta, entonces, agradecer a todos ellos por sus iluminadoras contribuciones e invitar al lector a sumergirse, tras la demora que han significado estas reflexiones introductorias, en las profundas aguas de la teoría del derecho contractual.

\section{Bibliografía}

Calabresi, G. y Melamed, A. D., Property rules, liability rules and inalienability: One view of the cathedral, Harvard Law Review, 1972.

Smith, S. A., Contract Theory, New York, Oxford University Press, 2004. 